\title{
The Correlation between Specific Biochemical Parameters, Radiological data and clinical sings for practicing laparoscopic cholecystectomy in the first 24 hours for acute cholecystitis. How safe it is?
}

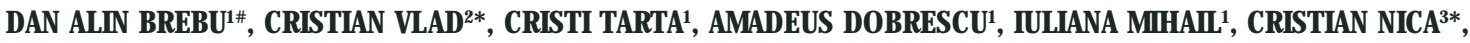 \\ LAZAR FULGER $^{1 *}$, CIPRIAN DUTA ${ }^{1}$ \\ IVictor Babes University of Medicine and Pharmacy, Department of Surgery, 2 Eftimie Murgu Sq., 300041, Timisoara, Romania \\ 2Victor Babes University of Medicine and Pharmacy, Department of Pharmacology, 2 Eftimie Murgu Sq., 300041, Timisoara, \\ Romania \\ ${ }^{3}$ Victor Babes University of Medicine and Pharmacy, Faculty of Medicine, 2 Eftimie Murgu Sq., 300041, Timisoara, Romania
}

The best timing of cholecystectomy on patients with acute gallbladder pathology is still unclearly defined. Some studies have reported that cholecystectomy during the index acute admission presents an increased morbidity rate, extended duration of stay and increased costs. The study below is aiming at finding the most accurate moment to practice the surgery when acute cholecystitis is confirmed. Consequently, 368 patients admitted to hospital from January 2013 to December 2015 with the diagnosis of acute cholecystitis (AC) who underwent cholecystectomy in the $2^{\text {nd }}$ Department of Surgery, Emergency County Hospital, Timi-oara, Romania constituted the two lots. The cases were retrospectively identified, introduced into the database and the data were subsequently analyzed according to various parameters. The study results reveal that laparoscopic cholecystectomy $(\mathrm{LC})$ in the first 24 hours is safe procedure on the majority of the cases. Also, our findings sustain that emergency cholecystectomy can reduce the length of hospital stay, having similar rates of conversion to open surgery, complications and outcome compared with a delayed operation.

Keywords: acute cholecystitis, biochemical parameters, laparoscopic cholecystectomy

Laparoscopic cholecystectomy (LC) can be defined nowadays the gold standard for the treatment of patients with symptomatic gallstones. $6.5 \%$ of men and $10.5 \%$ of women are affected by gallbladder stone disease [1] 1 - 4 $\%$ of these patients will develop gallstone related complications each year, first and foremost acute cholecystitis (AC) [2].

Early cholecystectomy was considered superior to open delayed cholecystectomy in the prelaparoscopic era, because of shortened hospitalization and recovery time, without increase of postoperative morbidity and/or mortality [3]. In the first decade of laparoscopic era, AC was considered a contraindication for a minimally invasive approach. Several studies have also reported the advantages and superiority of laparoscopic approach in terms of immunological aspects [4]. Currently, LC is indicated as the first therapeutic choice for patients with AC. Moreover, a recent meta-analysis suggests that early laparoscopic cholecystectomy (ELC) is beneficial and superior to any other treatment options [5]. A factor that makes the assessment of outcomes of early treatment difficult in the trials is that earlyis variably defined as a time period between $24 \mathrm{~h}$ to 7 days after the onset of symptoms or the time of diagnosis. Nevertheless, the optimal timing of ELC is still controversial. There are some guidelines that recommend performing surgery as soon as possible [6], but there is no consensus about the exact time for the intervention, although it is advised to operate within 24-72 $h$ of symptom onset [7]. The objectives of this study were: to establish the rate of early cholecystectomy among patients with $\mathrm{AC}$, to compare the outcome of patients undergoing immediate cholecystectomy within the first 24 h of symptom onset or delayed cholecystectomy ( $\geq 72$ h), and to identify predictive factors of complications after surgery.

\section{Experimental part}

Materials and methods

In this study, patients with $A C$ where evaluated retrospectively and all the data where statistically analyzed in order to establish correlations between the best timing and the risks for $\mathrm{LC}$ in the first $24 \mathrm{~h}$ after hospitalization. From January 2013 to December 2015 a total of 432 consecutive cholecystectomies for AC (according to Tokyo guidelines [8]) were performed in our $2^{\text {nd }}$ Department of Surgery, Emergency County Hospital, Timisoara, Romania. For this study, the lot exclusion criteria were absence of $\mathrm{AC}$, association of acute pancreatitis, uncertain timing of symptom onset, and undefined severity of AC. Forty six patients were excluded from the lot for the reasons described above. Form the total number of 386 cases of AC that fulfilled the lot inclusion criteria, for a relevant statistical analyze, we randomly selected an equal number of cases and divided in two separate groups depending on the time length for admission to surgery. Consequently, we selected 184 cases that underwent cholecystectomy in the first $24 \mathrm{~h}$ and 184 cases that were submitted to surgery at $72 \mathrm{~h}$ or more after admission to our Clinic. On admission, they showed right upper quadrant pain, fever, localized peritoneal irritation, ultrasound signs of $A C$ (distended gallbladder with thickened walls $>5 \mathrm{~mm}$, sandwich sign, fluid around the gallbladder), leukocytosis $>11 \times 10^{\circ} / \mathrm{L}$. This study respected the ethical standards specified in Helsinki Declaration.

\section{Surgical standard procedures}

The surgical procedures were defined as laparoscopic cholecistectomy and LC converted to open cholecystectomy (OC). LC was carry out through a standard four trocar operative technique (insertion of a $10 \mathrm{~mm}$ optical trocar in the umbilical region, a $10 \mathrm{~mm}$ trocar in the left 
subcostal area, a $5 \mathrm{~mm}$ operating trocar in the right lower quadrant, and a $5 \mathrm{~mm}$ retractor trocar in the epigastric region). The second surgical technique was the planned open cholecystectomy on some cases where this procedure was considered appropriate, and it was performed via a right subcostal laparotomy. A drain tube was placed in the subhepatic space and it was removed in the first postoperative day to the majority of the cases. All the procedures were performed by surgical teams that reunite senior surgeons with experience of over $100 \mathrm{LC}$ and residents/junior surgeons. If common bile duct (CBD) stones where suspected, the patients underwent preoperative magnetic resonance cholangiopancre atography (MRCP) and/or endoscopic retrograde cholangiopancreatography (ERCP) (fig.1). MRCP is preoperative recommended when gamma-glutamyl transferase (GGT) is higher than $100 \mathrm{U} / \mathrm{L}$, serum bilirubin value over $1.5 \mathrm{mg} / \mathrm{dL}$, and ultrasonographically determined diameter of the CBD between 4 and $8 \mathrm{~mm}$, without evidence of CBD lithiasys.

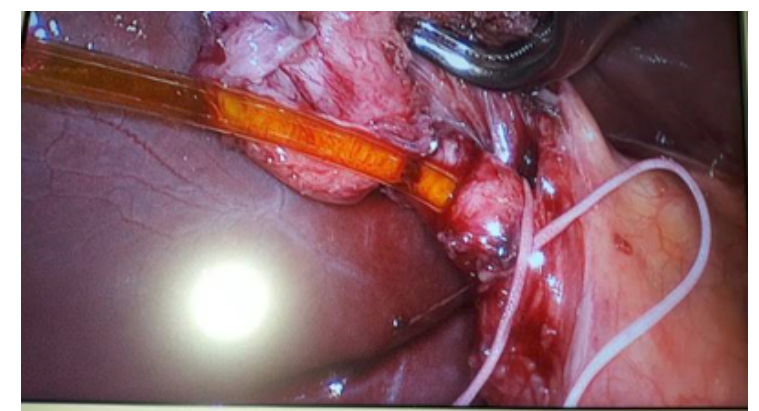

Fig.1. Image of intraoperatory direct cholangiopancreatography

Indications for performing preoperative ERCP were the following: elevated values of GGT ( $>100 \mathrm{U} / \mathrm{L}$ ) and serum bilirubin ( $>1.5 \mathrm{mg} / \mathrm{dL}$ ) and evidence of dilation of the CBD and/or presence of CBD stones at ultrasonography or MRCP $(>5 \mathrm{~mm})$. Postoperative morbidity was defined as complications that contributed to prolonged hospital stay or necessitated additional procedures. Following the Dindo - Clavien classification [9], for each complication a severity grade from 1 to 5 was assigned to each case. Bile leakage was defined as an outflow coming from the biliary tree that leads to bile externalization from the abdominal drainage or intraabdominal bile collection. Postoperative mortality was defined as the death of a patient while admitted to hospital.

\section{Group analysis by cholecystectomy timing}

All the patients included in the study lot were divided into two groups according to the timing of surgical operations: group no 1-patients undergoing cholecystectomy within the first $24 \mathrm{~h}$ after the initial signs - quick surgical intervention, and a second group of patients undergoing cholecystectomy on $\geq 72 \mathrm{~h}$ of symptom onset - temporized surgical intervention.

The following patients' data were retrospectively reviewed and used for analysis:

Preoperatory patient related factors were gender, age evaluated as a continuous and categorical variable $(\leq 65$, $>65$ years), body mass index (BMI) evaluated as categorical variable $\left(\leq 35,>35 \mathrm{~kg} / \mathrm{m}^{2}\right)$, associated pathology like diabetes mellitus (DM), chronic obstructive pulmonary disease (COPD), heart disease, and American Society of Anesthesiology (ASA) score.

The disease related factors were: white blood cell count (WBC), C-Reactive Protein (CRP), Alanine transaminase (ALT) and Aspartate transaminase (AST), Gammaglutamyl transferase (GGT), total serum bilirubin (TB),
Direct/conjugated bilirubin (DB) and Alkaline phosphatase (ALP) all evaluated as categorical variable, the length/ duration of symptoms at hospital admission, ultrasonographic findings following the Tokyo guidelines [8] (enlarged gallbladder along with thickened gallbladder wall, Murphy sign, fluid collection, pericholecystic or hepatic abscess, presence of choledocholithiasis). Additionally, some subsequent factors were analyzed: intraoperative surgical findings (acute or chronic cholecystitis, empyematous, gangrenous), operation time, postoperative complications, and conversion rate to OC, hospitalization stay, and histological findings.

\section{The statistical analysis of the obtained data}

The gathered data were reviewed as frequencies and proportions for categorical variables or as median for continuous variables. Continuous data were compared using Student'sttest. The main differences between groups were evaluated by chi square test or Fisher test when appropriate. Clinical and pathological characteristics were evaluated in a univariate model, and parameters with statistical significance were then evaluated in a multivariate analysis. Statistical relevance was defined as $P<0.05$. All the analyses were performed using GraphPad Prism 7 and SPSS 18 software.

\section{Results and discussions}

Initially, the patients from the two groups were comparable for demographics (gender and age), associated chronic pathology and also BMI and ASA score (table 1). Clinical and pathological type of the disease where also compared for the two study lots.

The distribution of the patients by gender show no statistical significance between the two groups, although we can observe a slightly predominance in the female population on both lots. The mean patients' age included in the first group was $48.54 \pm 11.04$ years and for the second group was $52.23 \pm 12.03$ years and was comparable on analysis with no statistically significant difference. The Body Mass Index (BMI) shows also no statistical relevance when comparing the patients from the two groups. Associated pathology occurs on $76(41.30 \%)$ cases in the first lot and $116(63.04 \%)$ in the second lot. Analyzing the data from this point of view, we found a statistical significance ( $p=0.003)$ comparing the two groups. Consequently, in the second study group where delayed LC was performed, the number of the patients that presented associated pathology was higher than in the first group: 116 (63.04\%) in the first lot vs. $76(41.30 \%)$ in the second one. Another interesting finding is that 147 representing $79.89 \%$ of the patients belonging to the second group, presented an ASA score of 1 and/or 2, and only 37 $(20.11 \%)$ of them were classified as ASA score $\geq 3$. Comparing with the results found in the first group, there is a statistically significant difference $(p=0.012)$ between the two lots. Following the same pattern and analyzing the data obtained by comparing the clinical type of $A C$, we also noticed a significant difference $(p=0.011)$ the first versus the second group. Hence, the majority of the patients enrolled in the second group (58.15\%) presented a mild form of AC. Of the total number of 368 cases, 128 had vesicular hydrops or inflammatory subhepatic block; 204 showed phlegmonous AC with or without pericholecystic fluid; 36 had gangrenous AC with localized peritonitis fluid. No statistically significance differences were detected for AC pathological type- simple, plegmonous (fig. 2), gangrenous (fig.3) in the two groups.

The median operation time was $0.39 \mathrm{~h}$, presenting no statistically significant difference between groups, but 


\begin{tabular}{|c|c|c|c|}
\hline & First $24 \mathrm{~h}$ & $\geq 72 \mathrm{~h}$ & $p$-Value \\
\hline Gender & & & 0.675 \\
\hline Male & $82(44.56 \%)$ & $86(46.73 \%)$ & \\
\hline Female & $102(55.43 \%)$ & $98(53.26 \%)$ & \\
\hline Age (Mean \pm SD) & $48.54 \pm 11.04$ & $52.23 \pm 12.03$ & 0.137 \\
\hline BMI $\left(\mathrm{kg} / \mathrm{m}^{2}\right)$ & & & 0.054 \\
\hline$\leq 35$ & $121(65.76 \%)$ & $103(55.98 \%)$ & \\
\hline$>35$ & $63(34.24 \%)$ & $81(44.02 \%)$ & \\
\hline Associated pathology & & & 0.003 \\
\hline Yes & $76(41.30 \%)$ & $116(63.04 \%)$ & \\
\hline No & $108(58.70 \%)$ & $68(36.96 \%)$ & \\
\hline ASA Score & & & 0.012 \\
\hline $1-2$ & $126(68.48 \%)$ & $147(79.89 \%)$ & \\
\hline$\geq 3$ & $58(31.52 \%)$ & $37(20.11 \%)$ & \\
\hline Clinical type & & & 0.011 \\
\hline Mild (1) & $72(39.13 \%)$ & $107(58.15 \%)$ & \\
\hline Moderate (2) & $89(48.37 \%)$ & $59(32.07 \%)$ & \\
\hline Severe (3) & $23(12.50 \%)$ & $18(9.78 \%)$ & \\
\hline Pathological type & & & 0.120 \\
\hline Simple & $55(29.89 \%)$ & $73(39.67 \%)$ & \\
\hline Phlegmonous & $108(58.70 \%)$ & $96(52.17 \%)$ & \\
\hline Gangrenous & $21(11.41 \%)$ & $15(8.15 \%)$ & \\
\hline
\end{tabular}

Table I

THE ANALYSIS OF THE

CLINICOPATHOLOGICAL DIFFERENCE BETWEEN THE TWO GROUPS OF PATIENTS

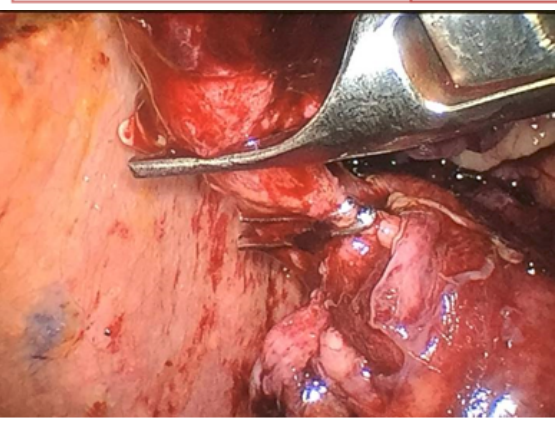

Fig. 2. Intraoperative image of phlegmonous acute cholecystitis having a trend toward a shorter duration in the first group. All the cases ( $N=368$ ) included in the study lot where firstly subjected to $\mathrm{LC}$, with an overall conversion rate of $6.25 \%$. There were no statistically significant difference regarding the type of cholecystectomy (OC vs LC) and conversion rates $(5.43 \%$ in the first and $7.06 \%$ in the second group respectively, $p=0.366$ ) (table 2 ).

The most important factors for conversion to $\mathrm{OC}$ were severe gallbladder inflammation (72\% of the cases), bleeding (20\%), peritoneal adherences (5.5\%) and suspected biliary tree lesion (2.5\%). The rate of conversion to open surgery was $6.25 \%$ (23 patients). No significant dissimilarity regarding the overall complication rate among the first and second lotwere found $15.97 \%$ in the first group vs $7.60 \%$ in the second group, $p=0.913$ ). Univariate analysis showed that the factors significantly associated with a higher rate of postoperative complications were age over 65 years, associated pathology (diabetes mellitus, heart or lung diseases), ASA score $\geq 3, A C$ grading, CRP $\geq 4$ $\mathrm{mg} / \mathrm{dL}$, presence of pericholecystic/hepatic fluid collection (abscess) at ultrasounds. On the other hand, total hospital

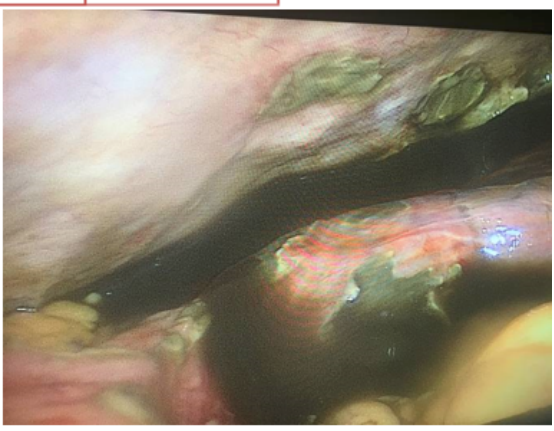

Fig. 3. Intraoperative image of gangrenous acute cholecystitis stay was longer ( $3.86 \pm 0.74$ versus $5.75 \pm 2.12$ days; $p=$ 0.032 ) in the delayed laparoscopic cholecystectomy group than in the early laparoscopic cholecystectomy group. Our findings are in correspondence with a related meta-analysis which shows that early laparoscopic cholecystectomy is preferable to delayed laparoscopic cholecystectomy when referring to total hospital stay reduction [10].

The paraclinical findings at hospitalization presented as mean values and standard deviations are depicted in table 3.

Among the eight biochemical markers evaluated in this study, the analysis of each of them revealed that only CRP $(p=0.022)$, TB $(p=0.026)$ and DB $(p=0.032)$ were statistically significant when comparing the values between the two groups. To choose whether is appropriate to perform an in urgencycholecistectomy, the surgeon must consider also the laboratory measurements of these parameters, correlated with the clinical and imaging findings.

\begin{tabular}{|c|c|c|c|}
\hline Characteristic & First $24 \mathrm{~h}$ & $\geq 72 \mathrm{~h}$ & $p$-value \\
\hline $\begin{array}{l}\text { Operation time (Minutes, } \\
\text { Mean } \pm \text { SD) }\end{array}$ & $38.52 \pm 21.94$ & $41.13 \pm 21.12$ & 0.871 \\
\hline Conversion rate & $10(5.43 \%)$ & $13(7.06 \%)$ & $0.366^{-}$ \\
\hline Hospital stay (Mean \pm SD) & $3.86 \pm 0.74$ & $5.75 \pm 2.12$ & 0.032 \\
\hline Complications & & & 0.913 \\
\hline Wound infection & $12(6.52 \%)$ & $14(7.60 \%)$ & \\
\hline Bile duct injury & $2(1.08 \%)$ & $3(1.63 \%)$ & \\
\hline Systemic & $8(4.34 \%)$ & $11(5.97 \%)$ & \\
\hline
\end{tabular}

Table 2

ANALYSIS OF THE OUTCOME DIFFERENCE BETWEEN THE TWO GROUPS OF PATIENTS 


\begin{tabular}{|c|c|c|c|}
\hline Laboratory findings & First 24 hours & $\geq 72$ hours & $p$-value \\
\hline $\begin{array}{r}\text { White blood cells-WBCs } \\
\qquad\left({ }^{*} 4-11 \times 10^{9} / L\right)\end{array}$ & $11.46 \pm 2.36$ & $12.65 \pm 2.98$ & 0.125 \\
\hline C-Reactive Protein-CRP (mg/dL) & $14.26 \pm 8.44$ & $5.02=6.28$ & $0.022^{--}$ \\
\hline Alanine transaminase-ALT $(* 0-41 \mathrm{U} / \mathrm{L})$ & $89.45=122.83$ & $86.57 \pm 68.32$ & 0.844 \\
\hline Aspartate transaminase-AST $(* 0-40 \mathrm{U} / \mathrm{L})$ & $110.57=203.85$ & $98.43 \pm 62.48$ & 0.417 \\
\hline Gamma glutamyl transferase-GGT $(* 10-71 \mathrm{U} / \mathrm{L})$ & $125.06=194.12$ & $130.22 \pm 254.64$ & 0.745 \\
\hline Total bilinubin ( $*<1.4 \mathrm{mg} / \mathrm{dL}$ ) & $0.54=0.40$ & $0.21 \pm 0.18$ & 0.026 \\
\hline Direct/conjugated bilirubin $(*<0.2 \mathrm{mg} / \mathrm{dL})$ & $0.46 \pm 0.36$ & $0.33 \pm 0.48$ & $0.032^{-}$ \\
\hline Alkaline phosphatase $(* 40-130 \mathrm{U} / \mathrm{L})$ & $88.31 \pm 48.65$ & $103.12 \pm 30.54$ & 0.056 \\
\hline
\end{tabular}

Table 3

CORRELATIONS BETWEEN THE

TWO STUDY GROUPS REGARDING LABORATORY FINDINGS,

*NORMAL RATIO INTERVAL

\begin{tabular}{|r|c|c|c|}
\hline Ultrasonography findings & First 24 h & $\geq \mathbf{7 2 ~ h}$ & $p$-value \\
\hline Thickness of the gallbladder wall & $132(71.73 \%)$ & $124(67.39 \%)$ & 0.192 \\
\hdashline Distended gallbladder & $158(85.86 \%)$ & $166(90.21 \%)$ & 0.216 \\
\hline Gallstones & $122(66.30 \%)$ & $131(71.19 \%)$ & 0.133 \\
\hline Pericholecystic fluid & $16(8.69 \%)$ & $11(5.97 \%)$ & 0.816 \\
\hline Positive Murphy sign & $88(47.82 \%)$ & $82(44.56 \%)$ & 0.745 \\
\hline
\end{tabular}

Table 4

CORRELATIONS BETWEEN THE TWO STUDY GROUPS REGARDING ULTRASONOGRAPHY FINDINGS

Preoperative ultrasound investigation illustrated thickened gallbladder wall in $69.56 \%$ of the total number of the cases from the two study lots $(\mathrm{N}=368)$, distended gallbladder in $83.93 \%$, gallstones in $68.75 \%$, pericholecystic collection in $19.6 \%$, pericholecystic or hepatic fluid in 7.33 $\%$, and positive Murphy sign in $46.19 \%$ of the patients. As presented in Table III, we found no statistically significant differences between the two groups regarding ultrasonography parameters, although those parameters can be correlated with the severity of the disease.

According to the Consensus Development Conference of the European Association for Endoscopic Surgery (EAES) [6], cholecystectomy for AC should be performed by LA and as soon as possible. Nevertheless, some randomized trials $[11,12]$ and meta-analyses $[13,10]$ lack a standardized definition of early surgical treatment. Early has been variably defined as anywhere from $24 \mathrm{~h}$ to 7 days after either the onset of symptoms or the time of diagnosis at hospital admission [14]. So, the optimal timing for the intervention is still controversial, even if the ideal time period is advised as within $72 \mathrm{~h}$ of symptom onset by other authors [15].

\section{Conclusions}

This study's results highlight the modern approach on cases of acute cholecystitis, where laparoscopic cholecystectomy can be safely performed within the first 24 hours from admission. Also, we found that the timing of surgery for $A C$ does not affect conversion rate and postoperative outcome. Consequently, the golden 72-h period should not represent an inflexible limit to perform LC for AC on evaluated cases, where the surgeon decides to practice in urgency cholecystectomy. Nonetheless, specific biochemical parameters, radiological data, correlated with clinical sings should be the guideline to manage these cases.

\section{References}

1. DUNCAN, CB., RIALL, TS. Evidence-based current surgical practice: calculous gallbladder disease. J ournal of Gastrointestinal Surgery,16, nr. 11, 2012, p. 2011-25

2. HALLDESTAM I., ENELL EL., KULLMAN E., BORCH K. Development of symptoms and complications in individuals with asymptomatic gallstones. British journal of surgery, 91, nr. 6, 2004, p. 734-8

3. NORRBY S., HERLIN P., HOLMIN T., SIÖDAHL R., TAGESSON C. Early or delayed cholecystectomy in acute cholecystitis? A clinical trial. British J ournal of Surgery, 70, nr. 3, 1983, p. 163-5.

4. WANG C., WANG Q., SUN D., CHEN X., SUN Y. Immunogenic alteration in laparoscopic common bile duct exploration. journal of surgical research, 187, nr. 1, 2014, p. 302-9

5. SKOURAS C., J ARRAL O., DESHPANDE R., ZOGRAFOS G., HABIB N., ZACHARAKIS E. Is early laparoscopic cholecystectomy for acute cholecystitis preferable to delayed surgery?: best evidence topic (BET). International Journal of Surgery, 10, nr. 5, 2012, p. 250-8 6. AGRESTA F., ANSALONI L., BAIOCCHI GL. et al. Laparoscopic approach to acute abdomen from the Consensus Development Conference of the Società Italiana di Chirurgia Endoscopica e nuove tecnologie (SICE), Associazione Chirurghi Ospedalieri Italiani (ACOI), Societa Italiana di Chirurgia (SIC), Società Italiana di Chirurgia d'Urgenza e del Trauma (SICUT), Società Italiana di Chirurgia nell'Ospedalità Privata (SICOP), and the European Association for Endoscopic Surgery (EAES). Surgical endoscopy, 26 nr. 8, 2012, p. 2134-64

7. AMBE P., WEBER SA., CHRIST H., WASSENBERG D. Cholecystectomy for acute cholecystitis. How time-critical are the so called golden 72 hours? Or better golden 24 hand silver 25-72 h? A case control study. World J ournal of Emergency Surgery, 1 nr. 60, 2014

8. YAMASHITA Y., TAKADA T., KAWARADA Y., NIMURA Y., HIROTA M., MIURA F., MAYUMI T., YOSHIDA M., STRASBERG S., PITT HA., DE SANTIBANESE. Surgical treatment of patients with acute cholecystitis: Tokyo Guidelines. Journal of hepato-biliary-pancreatic surgery, 14, nr. 1, 2007, p. 91-7

9. DINDO D., DEMARTINES N., CLAVIEN PA. Classification of surgical complications: a new proposal with evaluation in a cohort of 6336 patients and results of a survey. Annals of surgery, 240, nr. 2, 2004, p. 205

10. SIDDIQUI T, MACDONALD A, CHONG PS, JENKINS JT. Early versus delayed laparoscopic cholecystectomy for acute cholecystitis: a metaanalysis of randomized clinical trials. The American J ournal of Surgery, $195 \mathrm{nr} .1,2008$, p. 40-7

11. JOHANSSON M., THUNE A., BLOMQVIST A., NELVIN L., LUNDELL L. Management of acute cholecystitis in the laparoscopic era: results of a prospective, randomized clinical trial. J ournal of gastrointestinal surgery, 7, nr. 5, 2003, p. 642-5

12. KOLLA SB., AGGARWAL S., KUMAR A., KUMAR R., CHUMBER S., PARSHAD R., SEENU V. Early versus delayed laparoscopic cholecystectomy for acute cholecystitis: a prospective randomized trial. Surgical Endoscopy and Other Interventional Techniques, 18, nr. 9, 2004, p. 1323-7

13. GURUSAMY K., SAMRAJ K., GLUUD C., WILSON E., DAVIDSON BR. Meta analysis of randomized controlled trials on the safety and effectiveness of early versus delayed laparoscopic cholecystectomy for acute cholecystitis. British journal of surgery, 97, nr. 2, 2010, p. $141-50$

14. SKOURAS C., JARRAL O., DESHPANDE R., ZOGRAFOS G., HABIB N., ZACHARAKIS E. Is early laparoscopic cholecystectomy for acute cholecystitis preferable to delayed surgery?: best evidence topic (BET). International J ournal of Surgery, 10, nr. 5, 2012, p. 250-8

15. LEE AY., CARTER IJ., HOCHBERG MS., STONE AM., COHEN SL., PACHTER HL. The timing of surgery for cholecystitis: a review of 202 consecutive patients at a large municipal hospital. The American J ournal of Surgery, 195 nr. 4, 2008, p. 467-70

$\overline{\text { Manuscript received:4.10.2018 }}$ 